\title{
EDUCAÇÃO POLITICA DAS SENSIBILIDADES E ARQUITETURA ESCOLAR
}

- CYNTIA SIMIONI FRANÇA

http://orcid.org/0000-0002-1812-3696

Universidade Estadual do Paraná

NARA RUBIA DE CARVALHO CUNHA

http://orcid.org/0000-0003-1807-3825

Universidade Federal de Uberlândia

FABIO LUIZ DA SILVA

http://orcid.org/0000-0002-2106-9408

Universidade Norte do Paraná

RESUMO Este artigo aborda a relação entre educação política das sensibilidades na modernidade e a arquitetura escolar do início do século XX no Brasil. Toma-se como mote para esse exercício o prédio onde atualmente funciona o Colégio Marcelino Champagnat, em Londrina (PR). Dialogamos com documentos referentes ao edificio que abriga tal colégio, inserindo-os no cenário cultural dessa construção. Partiu-se do pressuposto de que os edifícios da escola moderna foram construídos de forma a dar visibilidade à modernidade e fixar no espaço urbano as novas formas de civilização. A arquitetura escolar faz parte do esforço para mobilizar a sociedade em favor da educação, pois para a elite dominante era necessário difundir novas atitudes e valores, entre os quais o de identidade nacional. Por isso a importância de compreendermos os edificios escolares como elementos de uma estratégia para a constituição diária das sensibilidades.

Palavras-chave Arquitetura escolar. Educação política das sensibilidades. História da Educação.

\section{ABSTRACT POLITICAL EDUCATION OF SENSITIVITY AND SCHOOL ARCHITECTURE}

This article discusses the relationship between political education of the sensitivities in modernity and the school architecture of the early twentieth century in Brazil. The building where the Marcellin Champagnat College currently operates in Londrina (PR) is taken as the 
theme for this exercise. We dialogue with documents referring to the building that houses the high school, inserting them in the cultural scene of this construction. It was assumed that the modern school buildings were constructed in such a way as to give visibility to modernity and to establish in urban space the new forms of civilization. School architecture is part of the effort to mobilize society in favor of education, since for the ruling elite it was necessary to spread new attitudes and values, including that of national identity. This goal would be achieved only in school. The school is, therefore, producer of subjects. That's the importance of understanding school buildings as elements of a strategy for the daily constitution of sensitivities.

Keywords: School architecture. Political education of sensitivities. History of Education.

\section{RESUMEN EDUCACIÓN POLITICAS DE SENSIBILIDADES Y ARQUITECTURA ESCOLAR}

Este artículo aborda la relación entre la educación política de las sensibilidades en la modernidad y la arquitectura escolar de principios del siglo XX en Brasil. El lema de este ejercicio es el edificio donde funciona actualmente el Colegio Marcelino Champagnat en Londrina (PR). Hablamos con documentos referentes al edificio que alberga esta escuela, insertándolos en el entorno cultural de este edificio. Se asumió que los edificios de la escuela moderna fueron construidos de tal manera que dieran visibilidad a la modernidad y fijaran nuevas formas de civilización en el espacio urbano. La arquitectura escolar es parte del esfuerzo para movilizar a la sociedad a favor de la educación, porque para la élite dominante era necesario difundir nuevas actitudes y valores, incluyendo el de la identidad nacional. Por lo tanto, la importancia de entender los edificios escolares como elementos de una estrategia para la constitución diaria de las sensibilidades.

Palabras clave: Arquitectura de la escuela. Educación política de las sensibilidades. Historia de la Educación.

\section{Introdução}

Desde o início da modernidade, a escola vem ampliando seu espaço na sociedade, ao ponto de ficarmos indignados com o fato de milhões de pessoas não terem acesso à educação escolar. A escola, por sua vez, é materializada em um edifício escolar construído de acordo com determinado tipo arquitetônico e determinadas intencionalidades. Garcia (2016) afirma que Arquitetura e Educação se constituem em elementos essenciais de nossa existência. 
Isso porque a escola é um dos lugares onde os cidadãos urbanos mais tempo ficam e onde grande parte das relações sociais ocorrem. Para essa autora, é na escola que ocorrem os primeiros reflexos da vida social. Por isso, os edificios escolares não podem ser pensados apenas como objetos físicos, mas, principalmente, como possuidores dos valores partilhados pela sociedade que os construiu. No entanto, é importante que se atente para o fato de que os valores não são construções naturais, mas socioculturais e em contínua reelaboração fomentada por "batalhas de percepções" (GAY, 1988) nas quais se evidenciam relações de poder e formas de resistência (THOMPSON, 1998).

Tomados em sua materialidade, os espaços escolares devem ser concebidos como produtos historicamente engendrados, nos quais se dá a "intersecção de discursos arquitetônicos, pedagógicos e históricos" (GRIMALDI e ALMEIDA, 2020, p. 4). O estudo da arquitetura escolar, portanto, se torna mais rico e complexo quando adota uma visão alargada que vai além da caracterização de estilo ou detalhamento de elementos arquitetônicos, bem como da concepção de um espaço que impõe normas e prescrições à revelia das experiências cotidianas de sujeitos que os formam e (trans) formam:

Superando essa discussão, a história da arquitetura escolar do século XXI vem ao encontro de uma perspectiva multidisciplinar. Arquitetos, historiadores e pedagogos passam a estudar esta materialidade da escola e enfocam diversas particularidades, tais como, a questão dos projetos dos edifícios, o ambiente como um elemento curricular, mas não exclusivamente, 0 espaço como responsável por questões de punição e vigilância, o mobiliário das escolas, o prédio na trama da cidade entre outros. (GRIMALDI e ALMEIDA, 2020, p. 13-14)

Como afirmam Grimaldi e Almeida (2020), em diálogo com autores como Antonio Viñao
Frago (1995), Michel de Certeau (1982), Michel Foucault (1995) e Paul Ricoeur (2007), a materialidade dos edificios expressa uma variada gama de elementos e símbolos culturais e estéticos que remetem a valores, regras e disciplina em processo de instituição social. No entanto, esses espaços são significados e ressignificados pelas práticas dos sujeitos que os habitam e rememoram experiências cotidianas neles vividas.

Nesse sentido, o estudo da arquitetura escolar permitiria questionar sobre os valores, as visões de mundo e sensibilidades que por ela são potencialmente endossadas, forjados ou sugeridos no espaço escolar em uma determinada época, ao mesmo tempo em que se poderia investigar sobre como esses mesmos valores, visões e sensibilidades são reelaborados ou, até mesmo, refutados pelos sujeitos em movimentos dinâmicos de relação com o outro - quer sejam relações entre os sujeitos e o prédio, tomado em seu aspecto físico, ou relações intersubjetivas que nele se desenvolvem - e em diferentes momentos.

Tal perspectiva de abordagem se aproxima da educação das sensibilidades, um movimento dinâmico que, como afirma Hadler (2007), na relação com palavras do historiador Peter Gay (1988), é um processo constante de formação de uma visão de mundo

[...] sempre inacabado, sempre em constituição; é um processo, de fato, de formação, de educação, uma educação que não se circunscreve apenas aos domínios da racionalidade intelectual técnica, da consciência objetiva, mas que atinge e perpassa os campos mal definidos da sensibilidade, tanto no que ela tem de mais visivel quanto de mais escondido e secreto. (HADLER, 2007, p. 21)

Para Oliveira (2018), a educação dos sentidos e das sensibilidades ganhou impulso "com a renovação historiográfica experimentada sobretudo a partir dos anos 1960 em todo o 
mundo" (p. 119). No entanto, a incorporação das noções de sentidos e sensibilidades nos estudos históricos remonta ao início do século XX, na Europa, em produções de autores representativos de diferentes filiações teórico-metodológicas e correntes historiográficas, desde os Annales à História Sociocultural Inglesa, passando pela Micro-história e incorporando até mesmo importantes nomes da filosofia da linguagem, como Walter Benjamin (1995; 2006) e Mikhail Bakhtin (2002). Já no campo da História da Educação, a educação das sensibilidades se destacou fortemente na última década, trazendo importantes contribuições, pois “[...] pode significar o refinamento do olhar para a lenta constituição de formas de agir e sentir e, também, pensar - gestadas no cruzamento das determinações estruturais e da volição individual." (OLIVEIRA, 2018, p. 125).

Para Galzerani (2013), a noção de educação das sensibilidades, formulada na perspectiva e através de diálogos com Gay (1988), Benjamin (1995) e Thompson (1981; 2002), configura-se como "produto e, ao mesmo tempo, produtora de práticas sociais, historicamente datadas dentre as quais a escola configura-se, apenas como uma delas" (GALZERANI, 2013, p. 143). Em sua obra, o olhar para os processos de educação das sensibilidades abarca diferentes ambiências, especialmente no espaço urbano, e procura evidenciar as relações entre os aspectos culturais, sociais, econômicos e políticos em movimento de afetação mútua. $E$, nesse sentido, investiga como se dá na modernidade capitalista a educação de sensibilidades do homem moderno economicamente ativo e politicamente dócil, sem perder de vista sua condição de autoria nesse processo, inclusive em práticas de resistência.

Cunha (2016), em diálogo com Galzerani (2013), afirma que as sensibilidades e as formas de ser tocado por/tocar o mundo pelos sentidos articulam aspectos objetivos e sub- jetivos, em movimento que rompe com a unilateralidade, ou seja, que não anula a atuação dos sujeitos, visto que eles participam ativamente dessa construção, imprimindo variadas formas de resistência, que vão desde a negativa à ressignificação (THOMPSON, 1998). Além disso, elas são elaboradas em um processo educativo que dialoga com a esfera produtiva, com as condições materiais de produção e de existência. Assim, nesse viés,

A educação das sensibilidades não se refere a uma educação para o sensivel ou para o estético, nem mesmo a uma investigação que tome as sensibilidades tão somente como objeto de pesquisa no campo da História. [...] a constituição das sensibilidades é lida numa perspectiva histórica, cultural e educacional, tanto porque se admite que elas sejam construções ancoradas no tempo e no espaço, quanto porque se percebe que seu engendramento é histórico, social e subjetivo, ou seja, elas não são nem naturais nem estritamente impositivas, mas reformulações contínuas, ligadas ao encontro dos sujeitos com o mundo, numa afetação mútua que vai moldando as experiências individuais [...]. (CUNHA, 2016, p. 33)

As experiências singulares são constituídas na relação com o social e trazem constantemente novos elementos, estabelecendo "um tráfego ininterrupto entre o que o mundo impõe e o que a mente exige, recebe e reformula" (GAY, 1988, p. 19).

Partindo desses pressupostos, este artigo investiga as relações entre a educação das sensibilidades na modernidade capitalista e a arquitetura escolar do início do século XX, no Brasil. Como objeto desse estudo de caso, realizamos um exercício interpretativo do edifício de uma escola construída na segunda metade da década de 1940. Trata-se do Colégio Estadual Marcelino Champagnat, na cidade de Londrina, interior do Paraná, cuja sede foi tombada como patrimônio histórico do estado em 2012. Considerado uma escola de quali- 
dade pela comunidade, esse estabelecimento recebe alunos da região central e de bairros distantes. 0 colégio Marcelino Champagnat se destaca entre as escolas de Londrina, seja por estar localizado no centro da cidade, pela trajetória histórica ou pela suntuosidade de sua arquitetura.

Para os que partilham da crença de que as escolas centrais são melhores do que as da periferia, estudar no colégio Champagnat pode ser elemento de distinção social. Simultaneamente, esse colégio também carrega uma aura monumental, que foi criada em torno dos prédios escolares no início do século XX (FARIA FILHO; VIDAL, 2000), o que nos permite tomá-lo como objeto de uma construção sociocultural e política da imagem da escola como lugar de progresso, civilidade, ensino, segurança e distinção social, fomentada no Brasil desde fins do século XIX (VEIGA, 2007; BUENO, 2008).

No processo de engendramento histórico dos grupos escolares do início do século XX, além da aura monumental, é possivel flagrar ainda, que em pequenos movimentos, um local permeado de tensões, conflitos, ambivalências, resistências (THOMPSON, 1998), que potencializam a compreensão das culturas escolares e da escolarização como processo marcado por uma tensão que "assinala a totalidade da cultura" (BERTUCCI; FARIA FILHO; OLIVEIRA, 2010).

Assim, as imagens construídas em torno desse colégio, na sua fundação ou na contemporaneidade, apresentam um amálgama de temporalidades (CAUQUELIN, 1982) reveladoras de práticas e sensibilidades urbanas engendradas coletivamente e em processo de constituição contínua, da qual os moradores participam ativamente, a que aqui identificamos, portanto, como educação política das sensibilidades, dada a sua dimensão de embate e conflito (GAY, 1988; GALZERANI, 2016).
A escola republicana como monumento do progresso e dos valores dominantes: educação política das sensibilidades

Diversos estudos no campo da História da Educação têm apontado a cooperação entre escola e os primórdios da República no Brasil na consolidação de valores ligados aos grupos dominantes. A educação e a instrução primária eram vistas como uma das mais "poderosas armas no combate às supostas consequências maléficas deixadas pelo Império e pelo trabalho escravo: a apatia frente à vida pública (e à respublica de uma maneira geral), a aversão ao trabalho manual, dentre outros" (FARIA FILHO, 2000, p. 27).

A organização de grupos escolares evidenciava uma preocupação com o controle das pessoas que o frequentavam; controle de seus corpos, gostos, gestos, suas relações com a pátria e com o outro. Desde o projeto arquitetônico, passando pelas práticas educativas até o nome escolhido para os grupos escolares, uma imagem de cidade/sociedade moderna, civilizada, organizada, higienizada e hierarquizada era cuidadosamente constituída, pela via racional e sensível. Veiga (2007) salienta que a escola, enquanto elemento de modernização republicana, corroborou a organização da sociedade aos moldes e valores das elites dominantes, sendo a educação estética de fundamental importância nesse processo:

Dentre as várias estratégias construídas para isso esteve a difusão da educação estética das populações presente nos conteúdos escolares, na organização do espaço urbano e escolar e na rotinização de acontecimentos promovedores de emoção estética, as festas escolares e as festas dos escolares na cidade, presentes nas primeiras décadas republicanas. 0 objetivo era dar visibilidade à modernidade, concretizar no espaço urbano novas atitudes e valores - a elegância, os bons costumes, o patriotismo, a civilidade. (VEIGA, 2007, p. 400) 
No entanto, deve-se ressaltar que tal educação estética não envolve apenas uma educação para o belo, mas o cultivo de hábitos e valores pela via sensivel. Nesse sentido, a escola não apenas ensina por meio de seus conteúdos disciplinares, mas também de suas práticas diversas, seus espaços, tempos e símbolos.

No Brasil, reformar o povo sem desestabilizar a ordem social, sem modificar o status quo era um desafio urgente para as elites republicanas, que passaram a investir na educação pública, gratuita e leiga, tomando a educação como "um símbolo integrado à república pela crença na sua capacidade de regenerar, moralizar, disciplinar e unificar as diferenças" (VEIGA, 2007, p. 405). Entre os vários meios de educação estética para o povo, as festas ou espetáculos cívicos promovidos pela escola merecem destaque, mas não só elas. A arquitetura dos prédios escolares também. Confere-se nessas atividades o privilégio dado ao olhar, à recepção ótica, não atada à esfera da contemplação, mas sobretudo do hábito.

Benjamin (1994), no tocante à arquitetura, argumenta que a recepção estética dos edificios se dá pelo uso, ou seja, pela recepção tátil, sendo que se efetua menos pela atenção do que pelo hábito. No que diz respeito à arquitetura, o hábito determina em grande medida a própria recepção ótica (BENJAMIN, 1994).

Nesse sentido, pode-se inferir que os prédios dos grupos escolares figuravam como elementos de constituição cotidiana de sensibilidades. Sensibilidades que deveriam se moldar aos anseios, valores e projetos políticos das elites dominantes. A isso não fugia, sequer, o estilo arquitetônico, pois tais construções eram erguidas com a função de propagandear os ideais do Estado, passando uma mensagem estética, cultural e ideológica. O objetivo era projetar "[...] um futuro, em que na República, o povo, reconciliado com a nação, plasmaria uma pátria ordeira e progressista" (FARIA FILHO; VIDAL, 2000, p. 25). Dessa ordem não escapavam a hierarquização de gênero, nem o controle dos corpos e dos gestos (GONDRA, 2007; BUENO, 2008).

Contudo, o movimento de constituição das sensibilidades não é unilateral, pois dele também participam outros sujeitos (nesse caso os estudantes) negando-o e/ou endossando-o. Grimaldi (2016), por exemplo, estudou a sensibilidade da memória estudantil em relação à arquitetura escolar e concluiu, entre outras coisas, que os alunos eram afetados pelo espaço que vivenciavam. Os edifícios escolares atuam como reguladores da vida e da sensibilidade estudantil, mas não de forma uniforme. O que significa afirmar que os alunos não estão passivos diante da arquitetura escolar.

Na obra A Experiência Burguesa: da Rainha Vitória a Freud, o historiador Peter Gay (1988) analisa o tenso movimento da educação das sensibilidades burguesas, investigando uma ampla diversidade de fontes documentais (cartas, registros médios, jornais, obras de arte etc.), nas quais ele identifica prescrições que determinavam as formas de ser, amar, odiar, desposar, enfim, de se comportar como membro da burguesia. Nessas mesmas fontes, Gay (1988) encontra as resistências, os desvios de sentido entre o prescrito e o assimilado, o que acarreta novas prescrições, novos desvios. Ele destaca, então, o caráter dinâmico da cultura burguesa e a constituição dessas sensibilidades nas relações sociais, nunca de forma unilateral. Dessa forma, ao analisar a arquitetura dos grupos escolares, ainda que existissem prescrições de comportamento e uma gama de esforços fosse adotada para que elas se efetivassem, era nas relações sociais e cotidianas que essas prescrições se redefiniam.

Ao nos determos na figura do colégio Champagnat, reconhecemos a sua participação num processo de educação política das sensibili- 
dades na cidade de Londrina, na consolidação da República, quando se solidificam os ideais de higienização, civilização, embelezamento, entre outros, que desde fins do século XIX "atenderam a demandas por iniciativas públicas que facilitassem as atividades produtivas" (GUIMARÃES, 2008, p. 246).

Nesse sentido, empreendemos a leitura de documentos referentes ao edificio que abriga tal colégio, inserindo-os no cenário cultural dessa construção. Movimentando nosso olhar numa relação entre presente e passado, a fim de contribuir com outros estudos que versam sobre a constituição de sensibilidades urbanas na modernidade, quer seja diretamente vinculada ao espaço escolar ou não. Procuramos nos manter atentos para capturarmos aspectos invisiveis da paisagem urbana (GALZERANI, 2016), muitas vezes varridos da superficie aparente dos discursos que projetam uma imagem que dela se constrói, ainda que continuem a tecer sua malha de relações.

\section{O edificio do Colégio}

\section{Champagnat: uma construção (da) para a cidade de Londrina}

A cidade de Londrina, que está localizada no interior do estado do Paraná, surgiu na primeira metade do século XX com anseios pelos ideais da modernidade e a promessa do progresso. Esses desejos eram disseminados por meio dos discursos da Companhia de Terras do Norte do Paraná (CTNP), que era uma empresa privada de origem inglesa e que loteou extensa região do estado. Tais discursos foram materializados em notícias de jornais, panfletos e folhetins com inúmeras propagandas comerciais acerca da venda de terras férteis. Eficiente propaganda desenvolvida no país e no exterior, desde a década de 1930, visavam seduzir as pessoas sobre as vantagens de comprar terrenos diretamente da CTNP.
As terras do norte do Paraná eram exaltadas como a "Terra da Promissão", o Eldorado, a nova Canaã, o paraíso prometido da fertilidade, da produção agrícola abundante, das oportunidades iguais de enriquecimento para "todos aqueles que quisessem trabalhar e prosperar", imagem que predominou até 1970 (ADUM, 2008, p. 4).

Fortuna (2013), em seu texto "Memória e Esquecimento Sobre a Cidade", explica que na década de 1970 a representação de Londrina como metrópole ganha força, pois a CTNP disseminou as imagens de progresso, lucro e harmonia entre campo e cidade. Antes de 1980, as narrativas sobre a cidade endossavam as representações da ordem dominante, tais como a de harmonia e de progresso e, em paralelo, privavam a história de Londrina da memória de outros grupos sociais, como os indígenas. Somente na década de 1980, o livro do jornalista José Jofilly, Londres, Londrina, questiona estas representações oficiais e o papel da CTNP "como empreendimento imobiliário de sucesso e denunciou um processo de colonização marcado pela dizimação dos indígenas e pela destruição predatória da mata. No entanto, este discurso contra-hegemônico não se constitui como memória hegemônica" (FORTUNA, 2013, p. 6).

Concomitante à manutenção de práticas culturais de apagamento das dimensões plurais das relações entre seus habitantes, muitas vezes marcadas pela exploração, era níti$\mathrm{da}$, nos discursos sobre a cidade de Londrina, a atmosfera de confiança no progresso. Tal progresso não abordava apenas aspectos técnicos, notadamente na esfera produtiva. Estritamente vinculada a ela, estavam os aspectos de cunho civilizatório, ligados ao corpo e às relações sociais, que se fizeram presentes por meio de diferentes dispositivos e ambientes, entre eles a escola. 
Quando o edificio que hoje abriga o Colégio Marcelino Champagnat (Figura 1) foi construído, na década de 1940, Londrina possuía mais de 60 mil habitantes e estava prestes a ver a população urbana superar a rural, o que aconteceu em 1948 (SILVA; MUZARDO, 2017). Para atender à demanda provocada pelo crescimento populacional, havia a necessidade de se construir um ginásio na cidade.

A construção de edificios específicos para os grupos escolares foi uma preocupação das administrações dos Estados que tinha no urbano o espaço privilegiado para a sua edificação, em especial, nas capitais e cidades prósperas economicamente. Em regra geral, a localização dos edificios escolares deveria funcionar como ponto de destaque na cena urbana, de modo que se tornasse visivel, enquanto signo de um ideal republicano, uma gramática discursiva arquitetônica que enaltecia o novo regime. (BENCOSTTA, 2001, p. 105)

Figura 1 - Edifício do atual Colégio Estadual Marcelino Champagnat, final da década de 1940

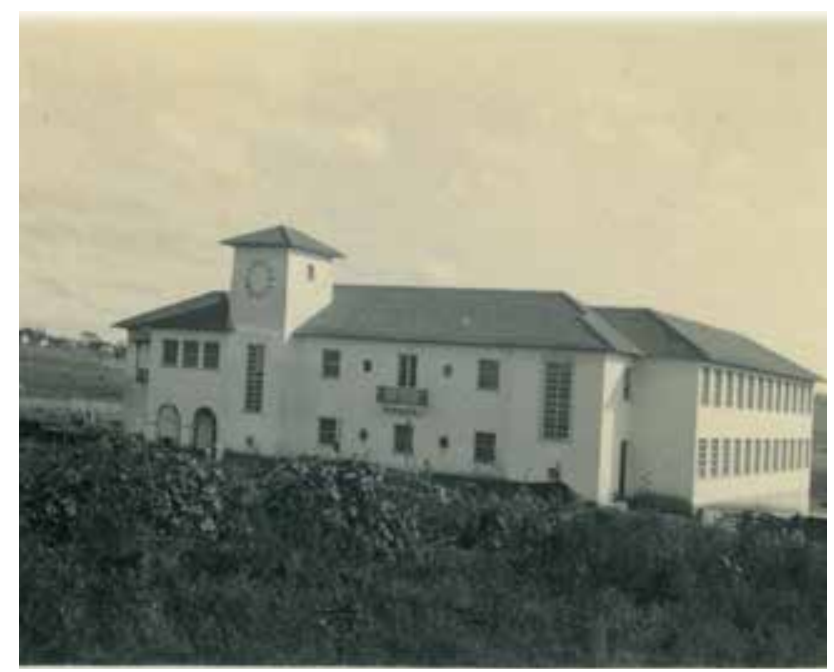

Fonte: acervo do Museu Histórico Padre Carlos Weiss, autor desconhecido.

Com a cidade em franco crescimento econômico, o Colégio Estadual Marcelino Champagnat foi criado. Era necessário oferecer para a população escola pública e gratuita. Porém, seu funcionamento inicial se deu em edificações de escolas privadas: o Colégio Marista e o Colégio La Salle (SANTOS, 2012).
O prédio da atual sede do colégio foi erguido para ser ocupado pelo Grupo Escolar Oswaldo Aranha, o que jamais ocorreu. Então, em primeiro de abril de 1947, instalaram-se duas escolas no mesmo edificio: a Escola de Professores de Londrina (atual Instituto de Educação de Londrina) e o Ginásio Estadual de Londrina (hoje, Colégio Estadual Professor Vicente Rijo). Após a transferência do Colégio Vicente Rijo, o Colégio Marcelino Champagnat se instalou no prédio atual, desde 1969.

Tal edifício foi construído em estilo neocolonial, embora a tendência da arquitetura escolar do período, marcado pelo Estado Novo de Getúlio Vargas, fosse a Art Déco. O estilo Art Déco surgiu na Europa, no período entre Guerras e esteve bastante presente em construções escolares da década de 1930, no Brasil, enquanto o estilo neocolonial foi mais adotado no início do século XX.

Segundo Bruand (1981), os adeptos desse estilo adotaram elementos da arquitetura barroca, numa mistura de influências portuguesas e brasileiras da época colonial: frontões curvos, janelas com requadros, entradas imponentes, treliças, balcões, pináculos, janelas em arco batido, entre outros, e foi a primeira tentativa de se obter uma arquitetura nacional. Um dos principais exemplares da arquitetura neocolonial é o edifício da Escola Normal do Rio de Janeiro, inaugurado em 1930. Apesar de ter sido criticado nas décadas seguintes pelos modernistas e pelos custos elevados (FARIA FILHO; VIDAL, 2000), essa opção arquitetônica esteve muito presente nas escolas públicas construídas no Paraná até a década de 1950 (SILVA; MUZARDO, 2017).

$A$ escolha pelo neocolonial não representava um desejo de retorno ao passado, o que soaria até mesmo incoerente com o processo de modernização vivido pela cidade de Londrina. Para Silva, a adoção do estilo neocolonial nas escolas públicas do Paraná, no período 
pós-Vargas, representa uma tentativa de adotar uma arquitetura que, ao mesmo tempo, “absorva a modernidade pedagógica e construa a identidade nacional; simultaneamente rompendo com o Art Déco dominante no período Vargas" (SILVA, 2012, p. 11).

Além de referências à arquitetura barroca e estilo colonial brasileiro, o edifício do Colégio Marcelino Champagnat incorporou elementos da arquitetura religiosa. A fachada, lembra algumas igrejas ou conventos, possui arcadas e balcão. A inspiração religiosa está presente também no pátio interno, com galerias superpostas que trazem à memória os antigos colégios jesuítas. A torre é outro elemento típico das construções religiosas, tendo as referências ao poder e ao domínio realçadas pela presença do relógio (SANTOS, 2012; SILVA, 2012).

De acordo com Faria Filho e Vidal (2000), o estilo neocolonial colaborava com ideais republicanos expressos por meio da educação escolar entre fins do século XIX e início do XX:

Em busca de uma maior homogeneização da mensagem estética, cultural e ideológica que os prédios escolares veiculavam, em 1926 foi realizado por Fernando de Azevedo para o jornal $\mathrm{O}$ Estado de $\mathrm{S}$. Paulo um inquérito sobre arquitetura colonial. Consultados arquitetos, educadores e médicos que emitiram pareceres sobre a arquitetura brasileira, o inquérito serviu a Azevedo para propor um padrão de arquitetura escolar: o neocolonial. Na sua concepção os edificios escolares deveriam trazer impressa na pedra a marca distintiva da brasilidade, de forma a desenvolver nas crianças o apego aos valores pátrios e aos signos da nacionalidade. Nesse sentido, recorrendo a uma pretensa tradição arquitetônica colonial, Azevedo indicava o estilo arquitetônico neocolonial como a arquitetura escolar por excelência. (FARIA FILHO; VIDAL, 2000, p. 28)

Um dos elementos mais comuns encontrados nas construções escolares da época era o formato em $U$, que garantia tanto um bom uso do terreno quanto a vigilância dos alunos. Mas principalmente demonstrava o poder e a importância da educação e do Estado, tornando “impossível não distinguir com clareza, na paisagem da cidade, um edificio imponente onde funcionava um grupo escolar construído nos primeiros tempos do regime republicano" (BUFA; PINTO, 2002, p. 18). Se o Estado pretendia expressar sua grandeza por meio da arquitetura escolar, seus objetivos pareciam ter sido atingidos com a construção de edifícios como aquele do colégio Marcelino Champagnat. Segundo Nogueira (2004), esse tipo de construção chamava atenção, desde sua construção, pela beleza arquitetônica:

[...] uma torre retangular encimada por quatro pequenas águas e ostentando um relógio. $\mathrm{Na}$ frente, destacam-se as sacadas com peitoril em colunas de madeira escura e um chafariz com bonitos azulejos portugueses nas cores branco e azul. Internamente, completando havia um bonito auditório com um piano de armário e, o mezanino. (NOGUEIRA, 2004, p. 128)

O engenheiro José Pedro da Rocha Neto, ex -aluno do colégio, assim descreveu o edifício no início da década de 1950:

[...] possuía dois pavimentos. Visualizando-o em planta, tinha a forma de um ' $U$ ' sendo que na perna esquerda estavam a secretaria, sala dos professores, salão de festas contendo um palco e, ao final, uma cantina [...]. Na parte frontal, também algumas salas destinadas à administração da escola e salas de aula. $\mathrm{Na}$ outra perna desse ' $U$ ', salas de aula tanto na parte inferior como superior sendo que nestas últimas havia um parapeito [...]. Além desse corpo principal, havia um anexo aos fundos, onde também existiam mais salas de aula, o laboratório e a sala de ciências naturais. (ROCHA NETO, 2006, p. 45)

Além disso, sua posição isolada em relação às construções vizinhas (ele ocupa uma quadra inteira) garantia-lhe o isolamento que identificamos com os retiros religiosos (Figura 2). 
Figura 2 - Edifício do atual Colégio Estadual Marcelino Champagnat, final da década de 1940

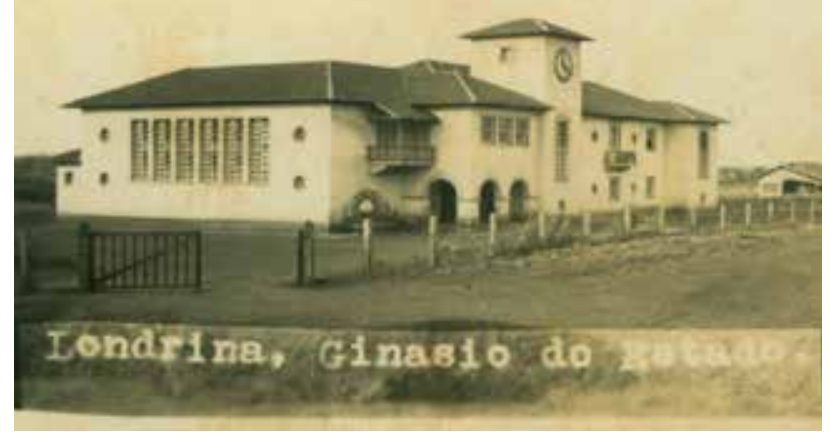

Fonte: acervo do Museu Histórico Padre Carlos Weiss, autor desconhecido.

Ademais, fazendo referência à cultura portuguesa, o estilo neocolonial endossava um projeto de nação excludente, que propagava a figura do branco europeu em detrimento de outros grupos étnico-raciais, como os negros e os indígenas. Essas imagens se não são $a b-$ solutamente contrastantes com ideais republicanos, como o culto à razão e aos princípios científicos, são, no mínimo, expressão de uma modernização complexa e seletiva.

\section{Diferentes formas de se habituar: entre prescrições e resistências}

Ao fazermos uma leitura dessas imagens (Figura 1 e Figura 2), que são fontes históricas importantes, e pensando na relação entre arquitetura escolar e práticas culturais na modernidade, encontramos no cenário de construção daquele edificio uma cidade marcada pelos desejos de modernização, convivendo com temporalidades múltiplas, em um processo tenso, tão sutil quanto agudo, de educação de sensibilidades.

Em diálogo com o historiador Edward Palmer Thompson (1998), compreendemos como a cultura moderna assimila e incorpora a disciplina regida pelo tempo do capitalismo. A partir de seu artigo “Tempo, disciplina de tra- balho e o capitalismo industrial", conseguimos estabelecer uma relação com nossas reflexões anunciadas, a partir do entendimento do espaço escolar na modernidade, de modo dialético, num intenso movimento entre presente e passado.

Thompson, ao estudar os trabalhadores de uma fábrica na Inglaterra, no século XVIII, e as transformações sócio-econômico-político-culturais do período industrial, compreendeu que tais mudanças foram sendo incorporadas no cotidiano dos operários. Além disso, o autor chama a atenção para o fato de escola se constituir como um espaço para as crianças serem disciplinadas e uma opção para saírem das ruas, sob a égide da ideia do uso econômico do tempo. A escola era, e continua sendo em muitos aspectos, entendida como um local de treinamento para o trabalho. 0 relógio presente nas fábricas como símbolo do controle do tempo e do comando também existe em muitas escolas na modernidade. Marcador temporal que garantia a ordem e a disciplina necessárias ao progresso da nação que se construía.

Refletindo nessa perspectiva thompsoniana sobre o espaço arquitetônico do Colégio Champagnat, identificamos que era um grande colégio para uma cidade que começava a pensar-se como moderna, embalada pelo capital vindo do "ouro verde". Marca uma época, sem dúvida de transição de um tipo de sociedade e educação, dominada pela elitização do ensino e de uma arquitetura escolar monumental. o colégio, constituído no bojo da modernidade, traz a figura marcante dessa sociedade, do tempo produtivo e controlado pelo relógio que indica esquadrinhamento de uma determinada funcionalidade produtiva. Tempo e espaço concebidos reciprocamente em íntima relação com os ideais modernos.

Percebemos que a cultura escolar não está dissociada do capitalismo industrial, porém, Thompson destaca que os costumes novos não 
sobrepõem aos costumes antigos. Pelo contrário, eles se imbricam em uma relação tensa, marcada ora pela dominação e/ou ora resistência. Os sujeitos selecionam as tendências culturais dominantes em suas experiências e incorporam elementos, bem como as negam, adequando-os às suas necessidades.

Isso implica pensar que nesse espaço escolar do Colégio Champagnat, os estudantes são atravessados pelos movimentos de tensão/ distensão e pelas fronteiras da resistência, conflitos e contradições. O que nos possibilita compreender que o colégio traz a imagem de um espaço escolar parecido com os claustros conventuais (CASTRO; IMAGUIRE, 2006), mas que era relido pelos alunos, que garantiam a existência de outras práticas culturais a contrapelo das tendências modelizadoras impregnadas nos programas, nas práticas e na arquitetura escolar. É isso que podemos flagrar no relato de José Pedro da Rocha Neto, do ex-aluno do colégio.

Era nesse local [parapeito da parte superior] que se posicionavam as meninas por ocasião dos recreios. Daquela posição as mesmas viam quem adentrava à cantina bem como os que circulavam no páteo interno situado entre as duas pernas do ' $U$ '. [...] Já era uma coisa tradicional, na nossa época, os que circulavam no páteo invariavelmente flertavam com as meninas que se posicionavam naquele parapeito em madeira situado no pavimento superior. (ROCHA NETO, 2006, p. 45-46)

É perceptivel que as práticas socioculturais são plurais no espaço do colégio e que estas são constituídas no interior das tensões. Portanto, dominação/resistência não são blocos engessados e constituídos mecanicamente, muito menos pertencentes a polos opostos: tanto a dominação como a resistência entrecruzam-se e se imbricam nessa relação conflituosa. Nesse sentido, as práticas socioculturais se inserem em um terreno de lutas, de ambiguidades, de contradições, no qual as di- ferentes concepções disputam espaços simbólicos e transformam-se.

O relato do ex-aluno do Colégio Champagnat é revelador. Nele, é possivel perceber o cotidiano escolar partilhado pelos estudantes e, ao mesmo tempo, como é recriado pelos sujeitos que constituem e são constituídos nesse espaço escolar. No depoimento, captamos como os alunos se reapropriam do espaço dominado pelas técnicas de produção sociocultural e alteram, assim, o seu funcionamento, "escapando caladamente do lugar que the é imposto" (CERTEAU, 2012, p. 41).

Para Michel de Certeau, o cotidiano é algo que nos cabe em partilha, a cada dia, como doação, pressão ou opressão. Ao mesmo tempo, "é aquilo que nos prende intimamente, a partir do interior. [...] É uma história a caminho de nós mesmos, quase em retirada, às vezes velada" (CERTEAU, 2012, p. 31). Lugares e espaços são concebidos por Certeau na seguinte perspectiva, um lugar é

[...] ordem (seja qual for), segundo a qual se distribuem elementos nas relações de coexistência. Aí se acha, portanto, excluída a possibilidade, para duas coisas, de ocuparem o mesmo lugar. Aí impera a lei do 'próprio': os elementos considerados se acham uns ao lado dos outros, cada um situado num lugar 'próprio' e distinto que define. Um lugar é, portanto, uma configuração instantânea de posições. Implica uma indicação de estabilidade. [...] existe espaço sempre que se tomam em conta os vetores de direção, quantidades de velocidade e a variável tempo. 0 espaço é um cruzamento de móveis. É de certo modo animado pelo conjunto dos movimentos que aí se desdobram. Espaço é o efeito produzido pelas operações que o orientam, o circunstanciam, o temporalizam e o levam a funcionar em unidade polivalente de programas conflituais, ou de proximidades contratuais. (CERTEAU, 2012, p. 184-185)

Falar de lugares e espaços na perspectiva abordada por Michel de Certeau (2012) é perceber que os lugares são transformados em 
espaços e vice-versa. É perceptivel que os estudantes (re)inventam criativamente o espaço escolar e se apropriam de "outras" mil e uma maneiras, mesmo atropelado pelas imposições da modernidade, em uma cidade que, desde a época do seu surgimento, já apresentava indícios de um esfacelamento das experiências (BENJAMIN, 1994). Instigante pensar que aquilo que estava posto como instrumento de dominação era utilizado pelos estudantes do Colégio Champagnat simplesmente para flertar com os meninos. Podemos perceber que as experiências dos estudantes podem ser construídas e modificadas na relação com outras práticas culturais.

Compreender as experiências e os sentidos que the são atribuídos pelos diferentes sujeitos no espaço escolar é entender que é possível resistir à dominação, mesmo por meio da incorporação dos elementos culturais dominantes, mas reinventando práticas outras, a partir dos interesses daqueles que apresentam as resistências.

Para Faria Filho e Bertucci (2009, p. 13), o processo de escolarização é marcado pela mesma tensão que marca a totalidade da cultura, ou seja, "[...] a escola exerce, simultaneamente, uma intensa atividade de apropriação, reorganização, desestruturação e desqualificação em relação às formas anteriores de produção cultural da pessoa educada". Nesse sentido, a arquitetura escolar apresenta-se como uma das estratégias na constituição de determinadas sensibilidades. No entanto, nesse esforço para a educação dos sentidos, a escola não é um poder absoluto. As releituras e as diferentes representações que cada grupo pode elaborar a partir da experiência no espaço e no tempo escolar demonstram a possibilidade de resistência. Portanto, o espaço escolar pode ser entendido com um campo tensionado, de disputas de forças, de representações, dominações e resistências em que diferentes lutas são (re) inventadas constantemente, movimentando o processo histórico. Sendo assim, o campo cultural é plural, ressignificado constantemente no cotidiano pelos sujeitos plurais.

\section{Considerações finais}

No Brasil, a partir do início da República, a educação passou por diversas mudanças, desde a adoção do ensino laico à reavaliação das formas de ensino-aprendizagem. Essas mudanças estiveram em estreita sintonia com o processo de modernização vivido no país, atento aos princípios positivistas e liberais. E os grupos escolares, inclusive em seus aspectos fisicos, tiveram importante papel nesse processo. Por um lado, os grupos escolares facilitam o controle sobre os sujeitos e sobre o processo de escolarização. Além disso, os prédios eram construídos de modo a garantir a eficácia desse controle e, também, favorecer a realização do ensino-aprendizagem em um ambiente mais condizente com as novas demandas da educação.

Os prédios escolares se tornam um marco na História da Educação, elementos essenciais de um movimento de mudanças que traz novos valores, deveres e condutas que devem ser assimiladas pela população, de modo a alavancar o progresso e garantir o sucesso da modernização do país. Os prédios escolares, inclusive através de sua materialidade, corroboram as iniciativas do Estado para implantar as sensibilidades modernas que, acreditavase, garantiriam o desenvolvimento do país.

Nesse sentido, este artigo pretendeu investigar, por meio de um estudo de caso, as relações entre a arquitetura escolar e a educação política das sensibilidades. Partiu-se do pressuposto de que os edifícios da escola moderna foram construídos de forma a dar visibilidade à modernidade e, ao mesmo tempo, fixar no espaço urbano as novas formas de civilização. 
A arquitetura escolar faz parte do esforço para mobilizar a sociedade em favor da educação escolar, pois para a elite dominante era necessário difundir novas atitudes e valores, entre os quais o de identidade nacional. Esse objetivo não seria atingido senão na escola. A escola é, portanto, produtora de sujeitos. Por isso a importância de compreendermos os edifícios escolares, como o do Colégio Marcelino Champagnat, como elementos de uma estratégia para a constituição diária das sensibilidades. Há um caráter político nesse objetivo, pois essas sensibilidades deveriam adequar-se aos anseios e valores das elites dominantes.

A arquitetura escolar permite aos historiadores da história da educação ir além do inventário e da descrição contextualizada dos diversos estilos arquitetônicos aos quais estiveram sujeitas as construções escolares. Paredes, portas, janelas e outros elementos arquitetônicos não estão dispostos de forma neutra. Pelo contrário, expressam visões de mundo e sensibilidades. O estudo da arquitetura escolar permite desvendar amálgamas de experiências presentes em tais edificios ou fomentadas por eles, as quais podem dar indícios de diversos conflitos sociais e culturais e evidenciar práticas de resistências, de não conformação, de embates cotidianos.

Ao abordar a relação entre arquitetura escolar e educação (política) das sensibilidades, entramos por uma via que entrecruza aspectos objetivos e subjetivos para dar ênfase a uma construção cultural moderna e dinâmica, que incorpora diferentes espaços e elementos, que envolve os sujeitos por inteiro, em suas dimensões racionais e sensiveis, os quais operam também a partir de resistências.

0 estudo da arquitetura escolar, sob esse prisma, endossa a concepção de cultura escolar como construção coletiva, dinâmica, mobilizadora de agentes internos e externos à escola. Ao ouvirmos as vozes dissidentes ou ao percebermos a polissemia dos discursos sobre e da escola, colaboramos para reafirmar a necessidade de fortalecer a construção de uma educação mais plural, democrática e participativa, um desafio posto e interpelado há muito no Brasil.

\section{Referências}

ADUM, Sonia Maria Sperandio Lopes. Historiografia norte paranaense: alguns apontamentos. In: ALEGRO, Regina Célia et al. Temas e questões para o ensino de história do Paraná. Londrina (PR): Eduel, 2008. p. 1-26.

BAKTHIN, M. Estética da Criação Verbal. São Paulo: Martins Fontes, 2002.

BENCOSTTA, Marcus Levy Albino. Arquitetura e espaço escolar: reflexões acerca do processo de implantação dos primeiros grupos escolares de Curitiba (1903-1928). Educar, Curitiba, UFPR, no 18, 2001, p. 103-141. Disponivel em: <http://www.scielo.br/pdf/ er/n18/n18a08.pdf.>. Acesso em: 17 jul. 2017.

BENJAMIN, Walter. Magia e Técnica, arte e política: ensaios sobre literatura e história da cultura. São Paulo: Brasiliense, 1994. [Obras Escolhidas, v. 1]

BENJAMIN, Walter. Rua de Mão Única. Tradução de Rubens Rodrigues Torres Filho e José Carlos Martins Barbosa. 5a ed. São Paulo: Brasiliense, 1995. (Obras Escolhidas, v. 2)

BENJAMIN, Walter. Passagens. Willi Bolle (Org. edição brasileira). Tradução de Irene Aron e Cleonice Paes Barreto Mourão. Belo Horizonte: Editora da UFMG/São Paulo: Imprensa Oficial do Estado, 2006.

BERTUCCI, Liane Maria; FARIA FILHO, Luciano Mendes; OLIVEIRA, Marcos Aurélio Taborda de. E. P. Thompson: história e formação. Belo Horizonte: Editora UFMG, 2010.

BRUAND, Yves. Arquitetura contemporânea no Brasil. São Paulo: Perspectiva, 1981.

BUENO, Maria de Fátima Guimarães. A história da educação: a cidade, a arquitetura escolar e o corpo. Cadernos do CEOM, Chapecó, Unochapecó, a. 21, 
no 28, p. 243-278, jun. 2008. Disponivel em: https:// bell.unochapeco.edu.br/revistas/index.php/rcc/article/view/164/72. Acesso em: 1 mar. 2020.

CASTRO, Elizabeth Amorin; IMAGUIRE, Marialba Rocha Gaspar. Colégios e educandários. Curitiba: Edição das autoras, 2006.

CAUQUELIN, Anne. Essai de Philosophie Urbaine. Presses Universitaires de France, 1982.

CERTEAU, Michel De. A invenção do cotidiano. Petrópolis: Vozes, 2012.

CERTEAU, Michel De. A escrita da história. Rio de Janeiro: Forense-Universitária, 1982.

FARIA FILHO, Luciano Mendes de. Dos Pardieiros aos Palácios: cultura escolar e urbana em Belo Horizonte na Primeira República. Passo Fundo: UPF, 2000.

FARIA FILHO, Luciano Mendes de; BERTUCCI, Liane Maria. Experiência e cultura: contribuições de E. P. Thompson para uma história social da escolarização. Currículo sem Fronteiras, Pelotas, UFel, v. 9, no 1, p. 10-24, jan./jun., 2009. Disponivel em: http:// www.curriculosemfronteiras.org/vol9iss1articles/1fariafilho-bertucci.pdf. Acesso em: 19 jul. 2017.

FARIA FILHO, Luciano Mendes de; VIDAL, Diana Gomes. Os tempos e os espaços escolares no processo de institucionalização da escola primária no Brasil. Revista Brasileira de Educação, Rio de Janeiro, ANPEd, no 14, p. 19-34, mai./ago. 2000. Disponivel em: https://www.scielo.br/scielo.php?pi$d=$ S1413-24782000000200003\&script=sci_abstract\&tlng=pt Acesso em: 15 jan. 2020.

FORTUNA, Cláudia Prado. Memórias e Esquecimentos sobre a Cidade. In: Simpósio Nacional de história - Conhecimento Histórico e Diálogo Social, XXVII. Natal-RN. Anais... Natal, UFRN, 2013, p.1-8. Disponível em http://www.snh2013.anpuh.org/resources/ anais/27/1371331791_ARQUIVO__Claudia_Fortuna_ anpuh.pdf. Acesso em: 1 fev. 2019.

FOUCAULT, Michel. A arqueologia do saber. Rio de Janeiro: Forense Universitária, 1995.

GALZERANI, Maria Carolina Bovério. 0 Almanaque, a locomotiva da cidade moderna: Campinas, décadas de 1870 e 1880. Campinas/São Paulo: UNICAMP/CMU
Publicações, 2016.

GALZERANI, Maria Carolina Bovério. Escola e conhecimento de História e Geografia: uma disciplina acadêmica e a educação das sensibilidades. Antíteses, Londrina, UEL, v. 6, no 12, p. 126-147, dez. 2013. Disponivel em: <http://www.uel.br/revistas/uel/index. php/antiteses/article/view/13345/13556>. Acesso em: 5 mai. 2020.

GARCIA, Patrícia Melasso. Pedagogias invisiveis do espaço escolar. 2016. 402f. Tese (Doutorado em Arquitetura e Urbanismo) - Faculdade de Arquitetura e Urbanismo, Universidade de Brasília, Brasília, 2016.

GAY, Peter. A Experiência Burguesa: da Rainha Vitória a Freud - A Educação dos Sentidos. São Paulo: Cia das Letras, 1988.

GONDRA, José G. Medicina, higiene e educação escolar. In: LOPES, Eliane Marta Teixeira; FARIA FILHO, Luciano Mendes e VEIGA, Cynthia Greive (Orgs.). 500 anos de educação no Brasil. Belo Horizonte: Autêntica, 2007. p. 519-551.

GRIMALDI, Lucas C. Na sensibilidade da memória estudantil: prédios e espaços escolares nas narrativas de estudantes de Porto Alegre/RS (1920-1980). 2016. 120f. Dissertação (Mestrado em Educação) - Programa de Pós-graduação em Educação, Universidade Federal do Rio Grande do Sul, Porto Alegre, 2016.

GRIMALDI, Lucas Costa e ALMEIDA, Dóris Bittencourt. Narrativas do espaço habitado: sensibilidades no estudo dos prédios escolares de Porto Alegre/RS (1940/1980). Revista História da Educação, Porto Alegre, ASPHE, v. 24: e99641, jan./abr. 2020. Disponivel em: https://www.scielo.br/pdf/heduc/ v24/2236-3459-heduc-24-e99641.pdf Acesso em: 15 jan. 2020.

HADLER, Maria Sílvia Duarte. Trilhos da Modernidade: memórias e educação urbana dos sentidos. 2007. 326 f. Tese (Doutorado em Educação) Programa de Pós-graduação em Educação, Universidade Estadual de Campinas, Campinas-SP, 2007.

NOGUEIRA, Amelia Tozzetti. De Norte a norte: uma trajetória de "contadini". Londrina: Edição da Autora, 2004. 
OLIVEIRA, Marcus Aurelio Taborda de. Educação dos sentidos e das sensibilidades: entre a moda acadêmica e a possibilidade de renovação no âmbito das pesquisas em História da Educação. Revista História da Educação, Porto Alegre, ASPHE, v. 22 no 55, p. 116-133, maio/ago. 2018. Disponivel em: https://www.scielo.br/pdf/heduc/v22n55/pt_22363459-heduc-22-55-00116.pdf . Acesso em: 15 jan. 2020.

GAY, Peter. A Experiência Burguesa: da Rainha Vitória a Freud - A Educação dos Sentidos. São Paulo: Cia das Letras, 1988.

RICOEUR, Paul. A memória, a história, o esquecimento. Campinas: Unicamp, 2007.

ROCHA NETO, José Pedro. 50 Anos depois: elaborado com vista ao cinquentenário dos formandos da turma ginasial de 1956, do antigo Colégio Estadual de Londrina. Londrina: edição do autor, 2006.

SANTOS, Tauany Rodrigues Nascimento dos. Apontamentos da História e Arquitetura do Colégio Estadual Marcelino Champagnat. 2012. 50 f. Trabalho De Conclusão de Curso (Graduação Em Pedagogia) Universidade Estadual de Londrina, Londrina, 2012.

SILVA, Fábio Luiz da; MUZARDO, Fabiane Tais. Escola pública em Londrina: civilização e barbárie. Curitiba: CRV, 2017.

SILVA, Fábio Luiz da. A arquitetura escolar como fonte para a história da educação. In: XIV Semana da Educação. Pedagogia 50 anos: da Faculdade de Filosofia, Ciências e Letras à Universidade Estadual de Londrina, 2012, Londrina. In: Anais... Londrina: Universidade Estadual de Londrina, 2012. v. único. p. s/p. Disponivel em: <http://www.uel.br/eventos/ semanadaeducacao/pages/arquivos/anais/2012/ anais/aescola/aarquiteturaescolar.pdf> Acesso em: 15 mai. 2020.

THOMPSON, Edward Palmer. Costumes em comum: estudos sobre a cultura popular tradicional. São Paulo: Companhia das Letras, 1998.

THOMPSON, Edward Palmer. Os Românticos: a Inglaterra na era revolucionária. Rio de Janeiro: Civilização Brasileira, 2002.

VEIGA, Cynthia Greive. Educação estética para o povo. In: LOPES, Eliane Marta Teixeira; FARIA FILHO, Luciano Mendes e VEIGA, Cynthia Greive (Orgs). 500 anos de educação no Brasil. Belo Horizonte: Autêntica, 2007. p. 349-422.

VIÑAO FRAGO, Antonio. Historia de la educación y historia cultural. Posibilidades, problemas, cuestiones. Revista Brasileira de Educação. Rio de Janeiro: ANPEd, n. 0, p. 63-82, Set./Dez. 1995. Disponivel em: <http:// www.anped.org.br/sites/default/files/rbe/ files/rbe_0.pdf> Acesso em: 15 dez. 2019.

Recebido em: 27.01.2020 Revisado em: 06.05.2020 Aprovado em: 12.05 .2020

Cyntia Simioni França é doutora em Educação pela Universidade Estadual de Campinas (UNICAMP). Membro do grupo Kairós, vinculado ao Centro de Memória UNICAMP (CMU), membro do Grupo de Estudos e Pesquisas (GEPEC) da Faculdade de Educação da UNICAMP. Docente do programa de Mestrado em História Púbica da Universidade Estadual do Paraná (Unespar) e do Mestrado Profissional em Ensino de História (PROFHISTÓRIA) da Unespar. E-mail: cyntiasimioni@ yahoo.com.br

Nara Rubia de Carvalho Cunha é doutora e mestre em Educação pela Universidade Estadual de Campinas (UNICAMP). Docente do Instituto de História da Universidade Federal de Uberlândia (UFU). Pesquisadora Grupo de Estudos e Pesquisas em Educação Continuada (GEPEC), da FE/UNICAMP, e do Grupo de Pesquisao Kairós: educação das sensibilidades, história e memória, vinculado ao Centro de Memória da mesma instituição, e do grupo Arquivos, Educação e Práticas de Memória: diálogos transversais, vinculado à Escola de Ciência da Informação da UFMG. E-mail: nrcdois@yahoo.com.br

Fabio Luiz da Silva possui doutorado em História Universidade Estadual Paulista (UNESP) campus Assis, mestrado em História pela Universidade Estadual de Londrina (UEL), graduação em História pela UEL, graduação em Administração de Empresas pela UEL. É professor de História do Colégio de Aplicação Pedagógica da UEL e de História Contemporânea na Pitágoras-Unopar. Docente do Programa de Pós-graduação em Metodologias para o Ensino de Linguagens e suas Tecnologias (mestrado e doutorado), da Pitágoras-UNOPAR. E-mail: fls.londrina@yahoo.com.br 